\title{
Effect of sepiolite on the quiescent and non-quiescent crystallization behaviour of the biodegradable poly(lactic acid) prepared via casting and melting
}

\author{
S. A. Cruz*, L. A. Onoue, C. M. Paranhos, E. Longo \\ Federal University of São Carlos, Department of Chemistry, Rod. Washington Luís, km 235, SP-310. São Carlos, Brazil
}

Received 12 February 2019; accepted in revised form 30 April 2019

\begin{abstract}
Poly(lactic acid) (PLA) is one of the most extensively investigated and used aliphatic polyesters due to some aspects such as biodegradability and biocompatibility. However, PLA has some disadvantages that restrict its applicability for instance its limited thermal resistance and low crystallization kinetics. In this work, nanoclay mineral sepiolite (Sep) was used to enhance the crystallization of PLA. The samples were prepared by casting and melting to evaluate the influence of the processing type on the PLA crystallization. For this purpose, the crystallization kinetics as a function of (i) Sep content and (ii) different types of processing was evaluated by polarized optical microscopy, flow-induced crystallization and differential scanning calorimetry under isothermal condition and glassy crystallization (Avrami model), X-ray diffraction and small angle X-ray scattering. The results of quiescent crystallization show that the presence of Sep enhanced the nucleation density leading to faster spherulites growing and lower crystallization half-time compared with pure PLA. The Sep also affects the flow-induced crystallization in different way. Altogether, the relevance of the present study lies in the fact that it sheds some light on how the Sep content, processing and molar mass of the initial precursor can affect the crystallization of PLA.
\end{abstract}

Keywords: nanocomposites, poly(lactic acid), sepiolite, crystallization

\section{Introduction}

In the last decade there has been a growing interest in materials from renewable sources as a solution to minimize pollution problems and reduce dependence on petroleum-derived polymers [1,2]. Polymers formed from lactic acid are among the most promising to achieve these goals. These materials are biodegradable, biocompatible and its monomer(lactic acid) comes from renewable sources such as sugar cane and corn starch. Poly(lactic acid) or poly(lactide) (PLA) is one of the most extensively researched and used aliphatic polyesters. PLA has great potential to replace of some polymers for industrial applications or as one of the main biomaterials for various biomedical applications [1-4].
Despite the mentioned advantages, PLA has some drawbacks that limit its applicability, such as limited thermal resistance and low crystallization kinetics. Thus, some efforts $[3,5-7]$ have been made to reduce the effect caused by its limitations, as for instance the insertion of inorganic fillers, such as talc [7], organically modified montmorillonite [2] and carbon nanotubes (CNT) [8] in the polymer matrix to increase the kinetics of quiescent crystallization by promoting heterogeneous nucleation processes. Tang et al. [8] studied the effect of the CNT content on the non-isothermal crystallization of PLA using time-solved synchrotron wide-angle X-ray diffraction (WAXD) and polarized optical microscopy (POM). The authors concluded that the presence of 
CNT promotes extra nucleating sites leading to high nucleation density for the subsequent crystal growth. Other studies concerning the use of nucleating agents to improve the crystallinity of PLA have been reported [6,9]. Alliota et al. [6] studied the influence of two kinds of aromatic sulfonate derivatives as nucleating agent for PLA. The use of this additive promoted a positive effect on the mechanical and crystallization properties. As in the study of Wu et al. [2], the predominant crystal type was $\alpha$-form as verified by XRD measurements. Li and Huneault [9] found that talc is a highly effective nucleating agent for PLA verified by the isothermal DSC data.

Although the quiescent crystallization in PLA has been widely studied $[6,9]$, the processing of thermoplastics (e.g., extrusion, injection, and 3D-printing) is performed under dynamic conditions. It is wellknown in the literature that dynamic conditions can accelerate the formation of nuclei, since the shear flow can orient the polymer chains. The flow-induced crystallization of PLA has received less attention when compared with some semicrystalline polymers such as polyethylene (PE) and polypropylene (PP). Some studies have been carried out that investigate the influence of nanoparticles on the crystallization kinetic of PLA under shear-conditions. Tang et al. [8] studied the effect of shear flow and carbon nanotubes content (CNTs) on the non-isothermal crystallization of PLA. An increase in the nucleation density is related to the anchoring effect of CNTs. Among the various nanoscale particles used and researched for application in polymers, sepiolite (Sep) has raised great interest in recent years due to its high surface area and acicular morphology [10]. Sep is known as a hydrated magnesium silicate clay with a structural formula of $\mathrm{Mg}_{8} \mathrm{Si}_{12} \mathrm{O}_{30}(\mathrm{OH})_{4}\left(\mathrm{H}_{2} \mathrm{O}\right)_{4} \cdot 8 \mathrm{H}_{2} \mathrm{O}$. Its structure (Figure 2) consists of a magnesium octahedral sheet between two layers of silica tetrahedra built between several blocks and oriented tunnels [10]. The good interaction of Sep associated to its dispersion capacity in the PLA matrix can increase the thermal stability while inducing the heterogeneous nucleation process.

As far as PLA/sepiolite nanocomposites are concerned, based on our knowledge, only few studies regarding the effect of sepiolite on the crystallization behavior of PLA have been reported in the literature [2]. Other studies [11, 12] have focused on the effect of sepiolite on the thermomechanical behavior of PLA. Wu et al. [2] studied the crystallization kinetics of PLA with Sep prepared by melt-extrusion process and concluded that Sep is an effective nucleating agent. The crystallization half-time was reduced and the most common crystal structure PLA sample formed was $\alpha$-form, indicating that Sep did not induce the formation of a new crystal form.

The aim of the present work was to investigate the influence of the Sep content on the crystallization behaviour of PLA under isothermal and quiescent/ non-quiescent conditions. Furthermore, the type of nanocomposites preparation, casting and melting, was evaluated. The most important issue is understanding how Sep can affect, after and before, the erasing of the thermal history of the samples prepared via casting and melting techniques.

\section{Materials and methods}

\subsection{Materials}

PLA from Natureworks ${ }^{\circledR}$ Ingeo $^{\text {TM }}$ (trade name 4042 D, Minnetonka, USA) was used as a polymer matrix (D content $\sim 6.0 \mathrm{~mol} \%, \bar{M}_{\mathrm{w}} \sim 130000 \mathrm{~g} \cdot \mathrm{mol}^{-1}$ ). The sepiolite was purchased from Fluka (trade name 70253, Saint Louis, USA). The solvent chloroform used in the casting method was purchased from Synth (Diadema, Brazil).

\subsection{Samples preparation: casting and melting}

The samples employed in this work were prepared via casting and melting. PLA solutions $(20 \% \mathrm{~m} / \mathrm{v})$ using chloroform were prepared under stirring by 12 hours. The Sep was added in 1, 3 and $5 \% v / w$. The solutions obtained were spread on glass plates to obtain films with $70 \mu \mathrm{m}$ of thickness and then, maintained in an oven at $70^{\circ} \mathrm{C}$ by 1 hour. Pure PLA and Sep were mixed manually and processed via melt using a thermokinetic mixer (Dries) from MH Equipamentos (Guarulhos, Brazil) during 5 minutes at $3000 \mathrm{rpm}$. After mixing, the samples were pressed by compression mold in a Carver press (Wabash, USA). The following conditions were employed: time $2 \mathrm{~min}$; clamping pressure 3 ton; temperature $160^{\circ} \mathrm{C}$ and average thickness $100 \mu \mathrm{m}$. Previously to the melt process, the samples were dried under vacuum at $80^{\circ} \mathrm{C}$ for 12 hours. The samples are named as pure PLA, PLA/S1.0, PLA/S3.0 and PLA/S5.0 according to the Sep content. The samples prepared by this method contained the same amount of Sep as described previously. A schematic of sample preparation is shown in Figure 1. 


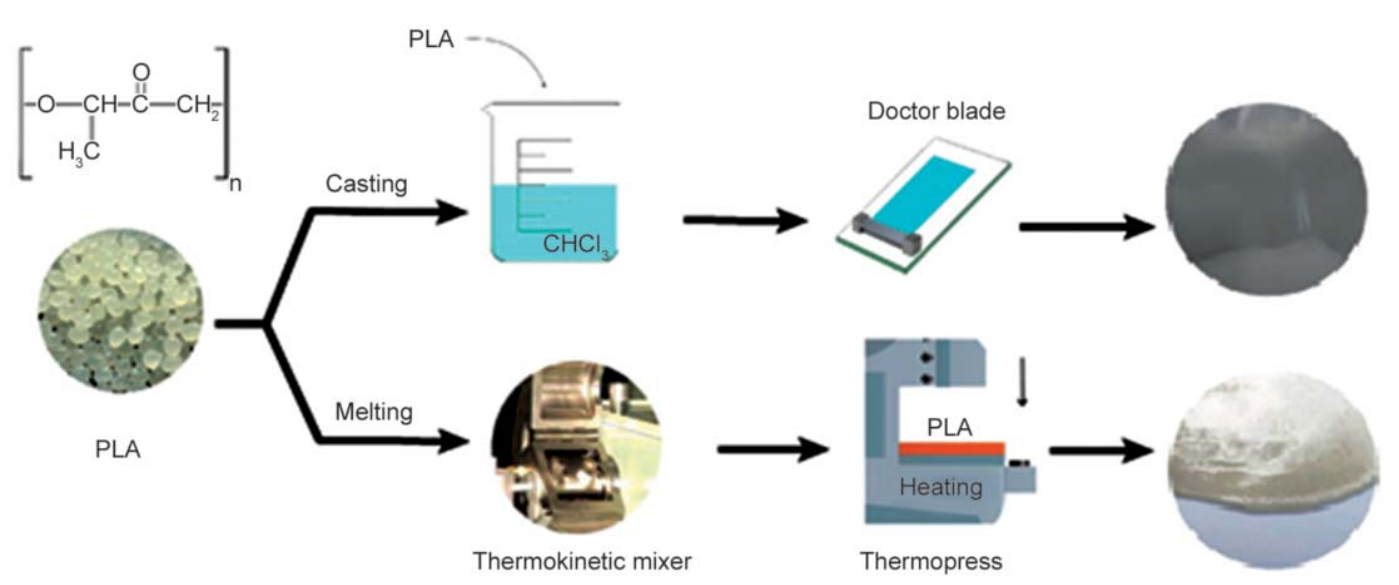

Figure 1. Schematic of sample preparation by casting and melting.

\subsection{Characterization}

\section{Polarized Optical Microscopy}

Polarized optical microscopy observation was carried out using a microscope from Olympus (trade name BX 50, Center Valley, USA) equipped with a Linkan (trade name THMS 600, London, UK) hot stage. The thickness of the films prepared by casting and melting is $\sim 35$ and $50 \mu \mathrm{m}$, respectively. The samples were heated to $180^{\circ} \mathrm{C}$ at $20^{\circ} \mathrm{C} \cdot \mathrm{min}^{-1}$ and held for 1 minute, then were cooled at the same rate to $120^{\circ} \mathrm{C}$. Subsequently the samples were cooled at a slower rate of $0.5^{\circ} \mathrm{C} \cdot \mathrm{min}^{-1}$ to $115^{\circ} \mathrm{C}$ and held for 120 minutes (isothermal crystallization). Photographs were taken every 20 minutes after achieving $115^{\circ} \mathrm{C}$.

\section{Rheometric analysis}

Rheological analysis and flow-induced crystallization were performed to verify the molar mass of pure $\operatorname{PLA}\left(\eta_{0}\right)$ and time to the beginning for crystallization, respectively. It was used an Anton-Paar (Modular Compact Rheometer, Graz, Austria) model MCR 302 , equipped with parallel plate geometry with $25 \mathrm{~mm}$ of diameter and gap of $1.0 \mathrm{~mm}$. The complex viscosity testing as a function of frequency was done in a range of 0.1 to $500 \mathrm{rad} \cdot \mathrm{s}^{-1}$ at $190^{\circ} \mathrm{C}$. It was used $2 \%$ strain which proved to be in the linear viscoelastic range.

To determinate the flow-induced crystallization behavior, the material was melted at $190^{\circ} \mathrm{C}$ and the sample was quenched down to $115^{\circ} \mathrm{C}$. After temperature stabilization, a shear rate of $0.1 \mathrm{~s}^{-1}$ was imposed to the sample and the shear tension was monitored as a function of time. From these measurements, the induction time for crystallization was calculated. According to Favaro et al. [13], this time is defined as the time at which the shear tension increased abruptly.

\section{Differential scanning calorimetry (DSC) and thermogravimetric analysis (TGA)}

All DSC measurements were performed in a Netzsch F209 Maia (Selb, Germany). The isothermal crystallization was performed at $115^{\circ} \mathrm{C}$ and under $\mathrm{N}_{2}$ purge $\left(50 \mathrm{ml} \cdot \mathrm{min}^{-1}\right)$. The samples were heated to $200^{\circ} \mathrm{C}$ (heating rate $20^{\circ} \mathrm{C} \cdot \mathrm{min}^{-1}$ ) and held for 3 minutes, then cooled down to $20^{\circ} \mathrm{C}$ at $60^{\circ} \mathrm{C} \cdot \mathrm{min}^{-1}$ and maintained at this temperature for 1 minute. Subsequently the samples were heated to the crystallization temperature of $115^{\circ} \mathrm{C}$ and held for 60 minutes. This method, named as glassy crystallization was adopted due to the low crystallization kinetics of PLA [5].

Another isothermal crystallization of the PLA-based samples was performed under the same conditions used in the POM analysis. The samples were first heated at $20^{\circ} \mathrm{C} \cdot \mathrm{min}^{-1}$ from room temperature to $180^{\circ} \mathrm{C}$ and held at that temperature for one minute. Then, the samples were cooled at the same rate to $120^{\circ} \mathrm{C}$. After reaching $120^{\circ} \mathrm{C}$, the samples were cooled at $0.5^{\circ} \mathrm{C} \cdot \mathrm{min}^{-1}$ to $115^{\circ} \mathrm{C}$ and held for 120 minutes.

The PLA samples were submitted to TGA analysis in order to detect the presence (or eventual loss) of the solvent (chloroform) used to prepare the films via casting. TGA Netzsch F209 Tarsus (Selb, Germany) was employed. For this purpose, about $10 \mathrm{mg}$ of PLA film sample was used. Each sample was subjected to the heat treatment from 40 to $190^{\circ} \mathrm{C}$ at a rate of $20^{\circ} \mathrm{C} \cdot \mathrm{min}^{-1}$ followed by an isotherm performed at $190^{\circ} \mathrm{C}$ for $20 \mathrm{~min}$ under a nitrogen atmosphere. 


\section{$X$-ray diffraction analysis}

The crystallographic identification of the PLA samples was obtained on a Bruker (model XRD $8 \mathrm{Ad}$ vance, Billerica, USA) diffractometer equipped with $\mathrm{CuK} \alpha(\lambda=0.15418 \mathrm{~nm})$ radiation source. The $\mathrm{X}$-ray diffraction (XRD) patterns were obtained at room temperature, and the generator was set up at $40 \mathrm{kV}$ and $25 \mathrm{~mA}$. Samples were scanned at a rate of $5^{\circ} \cdot \mathrm{min}^{-1}$ within the diffraction angle $2 \theta$ range of $5-30^{\circ}$.

\section{Small-angle X-ray scattering analysis}

The small-angle X-ray scattering (SAXS) experiments were performed in a Bruker AXS 2D Nanostar (Billerica, USA) with a $\mathrm{CuK} \alpha$ radiation, operating at $40 \mathrm{kV} / 35 \mathrm{~mA}$ in a range of $0.1-3.6 \mathrm{~nm}^{-1}$. The sample-to-detector distance was fixed at $106.4 \mathrm{~cm}$, and the time-resolved spectra of the PLA samples were collected every $1800 \mathrm{~s}$ for the samples processed by melting and $3000 \mathrm{~s}$ for the samples processed by casting.

\section{Results and discussion}

The crystallization kinetics as a function of (i) Sep content and (ii) different types of processing was evaluated by POM, flow-induced crystallization and DSC under isothermal conditions. In all cases the thermal history was erased. Both POM and DSC under isothermal conditions were carried out at the same temperature $\left(115^{\circ} \mathrm{C}\right)$ and cooling rate $\left(0.5^{\circ} \mathrm{C} \cdot \mathrm{min}^{-1}\right)$ for two hours. The Avrami model was also evaluated.

Figure 2 presents POM photomicrographs for pure PLA isothermally crystallized prepared via casting and melting, respectively.

The spherulite size is significantly reduced for the samples prepared via melting when compared to the

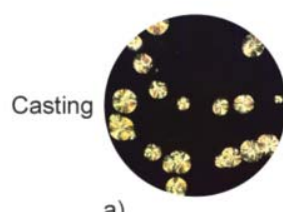

a)

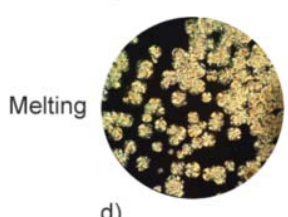

d)

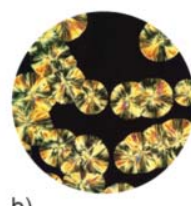

b)

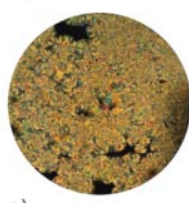

e)

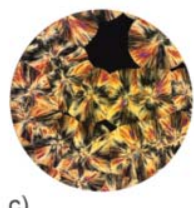

c)

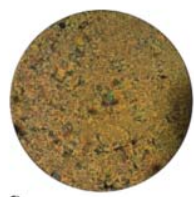

f) cast samples (Figure 2). It is well-known in the literature that under quiescent conditions the molar mass has pronounced effects on the rate of the nuclei formation [14]. Polymers chains with lower molar mass exhibit less time for nuclei formation and subsequent growth of crystals. To confirm this aspect the zero-shear viscosity $\left(\eta_{0}\right)$ was obtained, as well as the $\bar{M}_{\mathrm{w}}$, from the Equation (1) $[15,16]$ :

$\eta_{0}=K M_{\mathrm{w}}^{3.4}$

At $190^{\circ} \mathrm{C}, K=2.5 \cdot 10^{-14} \mathrm{~Pa} \cdot \mathrm{s} \cdot \mathrm{g}^{-1} \cdot \mathrm{mol}^{-1}$. Based on the obtained results from the viscosity as a function of frequency (Figure 3) and Equation (1) for the pure PLA, it was found that the $\bar{M}_{\mathrm{w}}$ is 333400 and $525800 \mathrm{~g} \cdot \mathrm{mol}^{-1}$ for the samples prepared by casting and melting, respectively. In the melting samples the high temperatures and intensity of shear rates due to the mechanical processing resulted in a degradation process by scission chains decreasing its molar mass. Figure 4 shows a comparison between pure PLA and PLA/Sep samples prepared by isothermally crystallized casting at $115^{\circ} \mathrm{C}$ for 80 minutes. An increase of nucleus density and greater amount of spherulite with reduced size can be observed when compared with pure PLA. This is due to the increase in the number of nucleating sites when sepiolite is added, indicating that it acts as a potential nucleating agent. Consequently, the crystallization kinetics are accelerated as observed in Figure 4, by the higher density of spherulites formed, especially for samples with 3 and $5 \%$ Sep. The samples with 3 and $5 \%$ of Sep present similar behaviour of crystallization and size of crystal. These results are in agreement with the isothermal DSC curves results, once both samples present comparable time for crystallization.

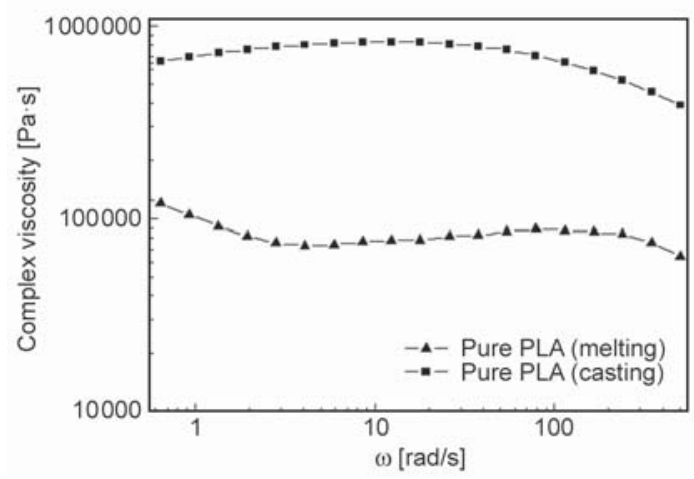

Figure 3. Complex viscosity of the pure PLA prepared by casting and melting as a function of frequency. ing and melting, respectively after being isothermally crystallized at $115^{\circ} \mathrm{C}$ : (a, d) $40 \mathrm{~min}$, (b, e) $80 \mathrm{~min}$ and (c, f) $120 \mathrm{~min}(40 \times)$. 


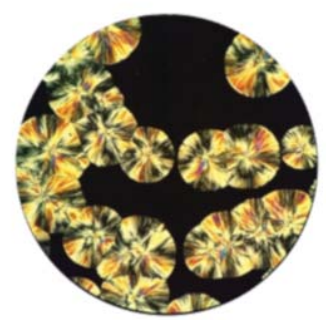

a)

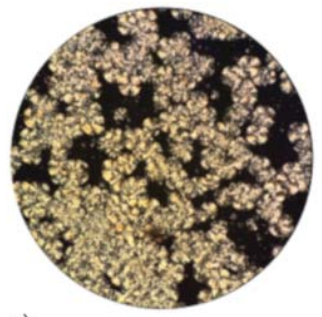

c)

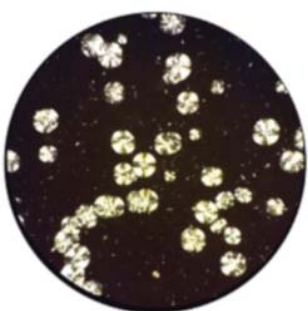

b)

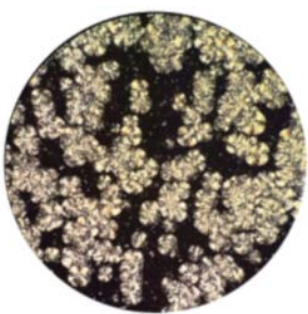

d)

Figure 4. POM of the PLA samples prepared by casting in isothermally crystallized at $115^{\circ} \mathrm{C}$ for 80 minutes: (a) pure PLA, (b) PLA/S1.0, (c) PLA/S3.0 and (d) PLA/S5.0 (40×).

Figure 5 shows the POM micrographs obtained for the samples prepared via melting and submitted to the same conditions as those prepared by casting. The samples incorporated with Sep showed, as expected, a size reduction of the spherulite, indicating a faster crystallization kinetics when compared to the casting processing. As previously described, this result may be associated with the reduced molar mass as a result of the melting processing. Moreover, for the melt-processed PLA, with the addition of Sep at

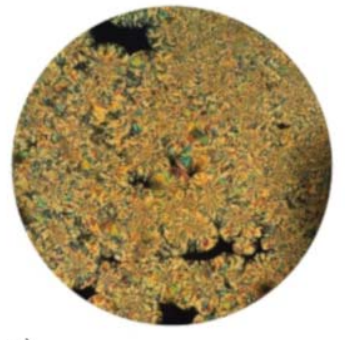

a)

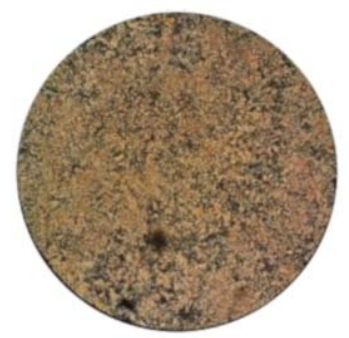

c)

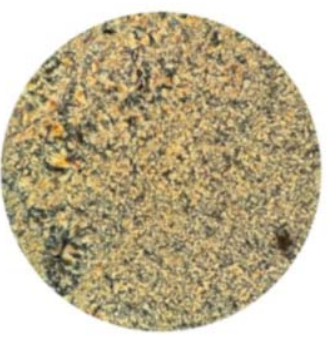

b)

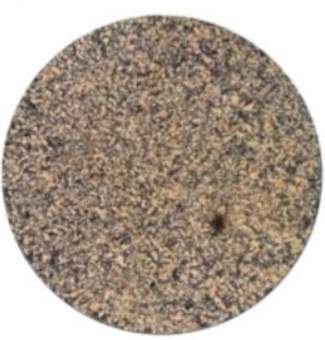

d)

Figure 5. POM of the PLA samples prepared by melting in isothermally crystallized at $115 \mathrm{C}$ for 80 minutes: (a) pure PLA, (b) PLA/S1.0, (c) PLA/S3.0 and (d) PLA/S5.0 (40×).

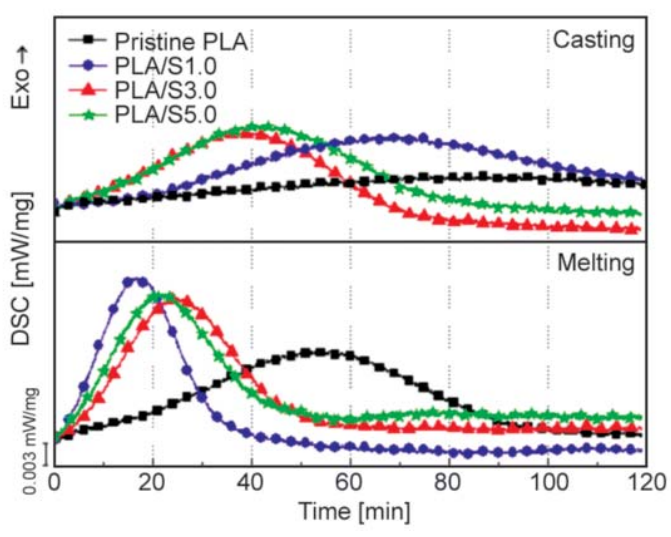

Figure 6. Isothermal DSC curves of PLA and PLA-Sep samples prepared via casting and melting.

any of the concentrations studied, the crystallization process was practically complete in 80 minutes.

The isothermal DSC curves obtained under the same temperature of POM (at $115^{\circ} \mathrm{C}$ ), are shown in Figure 6.

The results presented in Figure 6 indicate that total crystallization occurs at a time scale comparable to POM results, since in both cases the measurements were done under the same cooling rate. The higher the sepiolite content, the faster is the crystallization process. Considering that the slope of the initial isothermal DSC curves at $115^{\circ} \mathrm{C}$ can be directly related to the rate of crystallization process of the samples, the results showed that the Sep contributed to accelerate the crystallization processes. Also, it was observed that the crystallization of the melting samples was completed before $80 \mathrm{~min}$, as observed in POM micrographs. Moreover, Sep reduces the time interval between the beginning and the end of the crystallization processes, especially for the melting samples.

Pure PLA and its nanocomposites were analysed under glassy crystallization and fractional crystallization $\left(X_{\mathrm{t}}\right)$ as a function of time was calculated based on Avrami model (Equation (2)):

$X_{\mathrm{t}}=1-\exp \left[-k(t)^{n}\right]$

where $k$ is kinetic constant and $n$ is the Avrami exponent.

Figure 7 shows the curves of fractional crystallization as a function of time for the samples obtained by casting and melting. It can be seen that the melting samples show faster crystallization kinetics when compared to the casting samples, corroborating the 

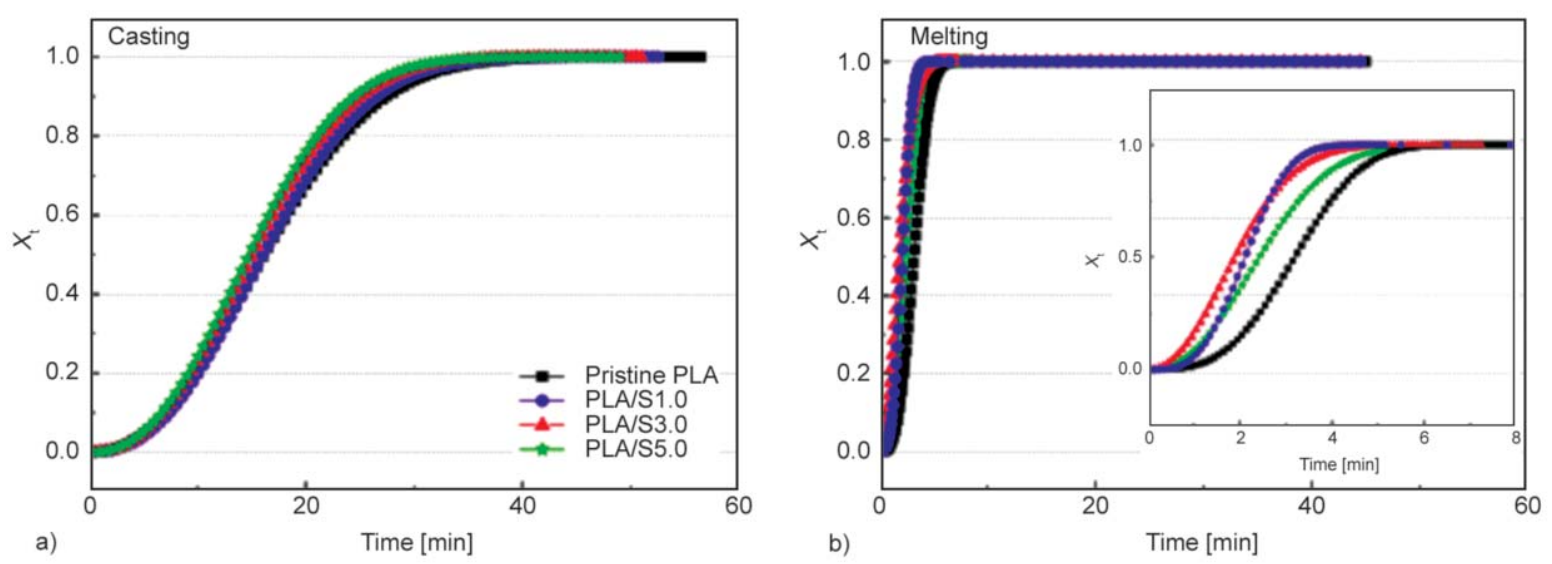

Figure 7. Relative crystallinity curves $\left(X_{\mathrm{t}}\right)$ as a function of time for the isotherm crystallization at $115^{\circ} \mathrm{C}$ for the samples processed by casting (a) and melting (b) using the glassy method.

effect of the decrease on the molar mass, verified previously by POM. Besides, the presence of Sep also contributes to the increase in crystallization rate, since the time required to reach the same $X_{\mathrm{t}}(0.95)$ for pure PLA is longer than PLA/Sep samples (Table 1). As described previously, the molar mass plays an important role in the crystallization process and consequently the type of processing.

Table 1 summarizes the Avrami data ( $k$ and $n$ ) as well as the crystallization half-time $\left(t_{1 / 2}\right)$. The samples obtained via melting exhibit lower $t_{1 / 2}$ when compared to the casting samples.

Avrami exponents $(n)$ are close to casting samples (2.3-2.5), indicating that the mechanism of nucleation and crystal growth dimensionality are two-dimensional based on instantaneous and sporadic nucleation. On the other hand, melting samples (pure PLA and PLA/S1.0) show three-dimensional sporadic growth or a combination of sporadic and simultaneous nucleation growth. Higher Sep content leads to similar behaviours of casting samples.

Usually, the crystallization behaviour is modified as a function of the shear flow imposed on the sample.

Table 1. Crystallization kinetics data based on Avrami method.

\begin{tabular}{|c|c|c|c|c|c|c|}
\hline Sample & Process & $X_{\mathrm{t}}$ & $\begin{array}{c}t \\
{[\min ]}\end{array}$ & $\begin{array}{c}\left(k \cdot 10^{-4}\right)^{n} \\
{[1 / \mathrm{min}]}\end{array}$ & $n$ & $\begin{array}{c}t_{1 / 2} \\
{[\mathrm{~min}]}\end{array}$ \\
\hline Pure PLA & \multirow{4}{*}{ Casting } & 0.95 & 30.8 & 10.40 & 2.3 & 16.7 \\
\hline PLA/S1.0 & & 0.95 & 29.6 & 7.00 & 2.5 & 16.7 \\
\hline PLA/S3.0 & & 0.95 & 28.3 & 9.18 & 2.4 & 15.3 \\
\hline PLA/S5.0 & & 0.95 & 27.4 & 9.62 & 2.4 & 15.3 \\
\hline Pure PLA & \multirow{4}{*}{ Melting } & 0.95 & 5.1 & 1520 & 3.2 & 3.4 \\
\hline PLA/S1.0 & & 0.95 & 3.4 & 569 & 3.3 & 2.1 \\
\hline PLA/S3.0 & & 0.95 & 3.8 & 1640 & 2.2 & 1.7 \\
\hline PLA/S5.0 & & 0.95 & 4.6 & 816 & 2.4 & 2.2 \\
\hline
\end{tabular}

In real processing conditions, this may be an important factor to consider, since crystallization occurs under flow conditions. The induction time can be determined by studying flow-induced crystallization. The induction time is described by the point where viscosity increases abruptly tending to infinity and indicates solid behaviour of the material. Coppola et al. [17] described that induction time is approximately proportional to the inverse of the nucleation rate.

It is well known that the crystalline structure formed in shear-induced conditions differs from those formed by quiescent ones. The shear flow could induce polymer chain orientation and form the primary nuclei precursors. The efficiency of the crystallization process was related to (i) shear-induced formation of nuclei and (ii) time of relaxation. So, the higher the molar mass the greater the alignments of the chains because they exhibit longer relaxation times [8, 14]. Although it is an important aspect, the relationship between molar mass and flow induced crystallization is not fully approached in the literature for PLA [14].

The behavior of the shear stress as a function of time after a predefined strain, as well as the induction times for the beginning of the shear-induced crystallization is shown in Figure 8.

Figure 8 shows that the pure PLA processed by casting and melting exhibits different behaviour associated to induced flow crystallization. Pure PLA and PLA/S1.0 obtained by casting does not crystallize in the test time. On the other hand, pure PLA obtained by melting presents lower induction time. This parameter is strongly dependent on the entropy of the system, which refers to the number of entanglements, as well as the mobility and diffusivity of the chains, and therefore the Deborah number. It can be 


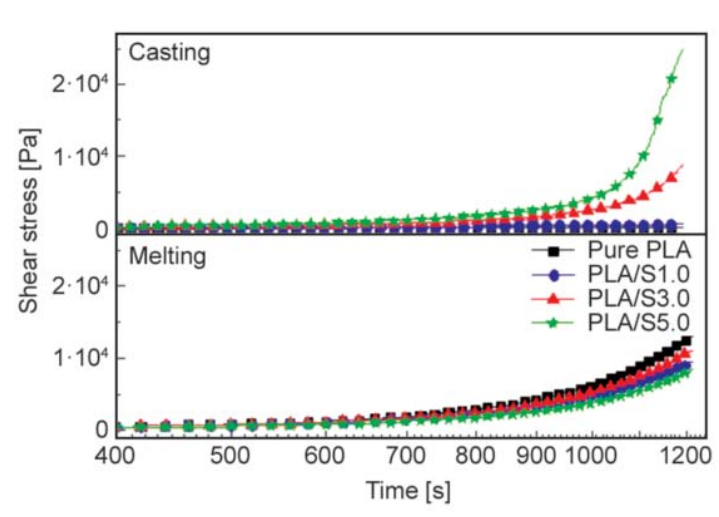

Figure 8. Shear stress as a function of time for pure PLA and PLA-Sep samples prepared via casting and melting.

hypothesized that the presence of residual chloroform plays an important role on the induction time and then in the molecular mobility. To prove the presence of chloroform in the casting samples even after it had been submitted to a complete melt, TGA analysis was performed (Figure 9) simulating the thermal history of the conditions applied in the flowinduced tests. The results of mass loss observed in the dynamic step could be caused by the release of chloroform from the casting samples.

Surprisingly, the presence of Sep affects the induction time in different way with the increase of Sep content: (i) for the melting samples an increase in the crystallization time was observed and, (ii) for melt a decrease in this parameter. The first step in the flow-induced crystallization is the formation of a fibrillar nucleus. In the melting nanocomposites the chain alignments were restricted by the presence of Sep, resulting in the increase of crystallization time. On the other hand, regarding the nanocomposites prepared by casting, it seems that the presence of residual chloroform can promote an increase in molecular mobility. As Sep presents a high specific

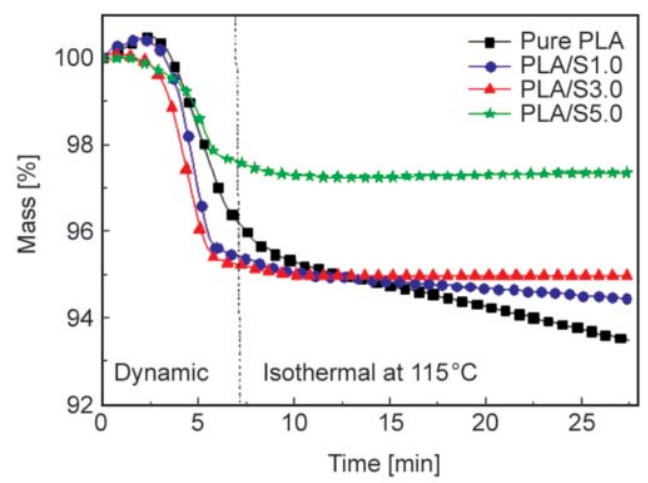

Figure 9. Thermogravimetric curves as a function of time for the samples prepared by casting.

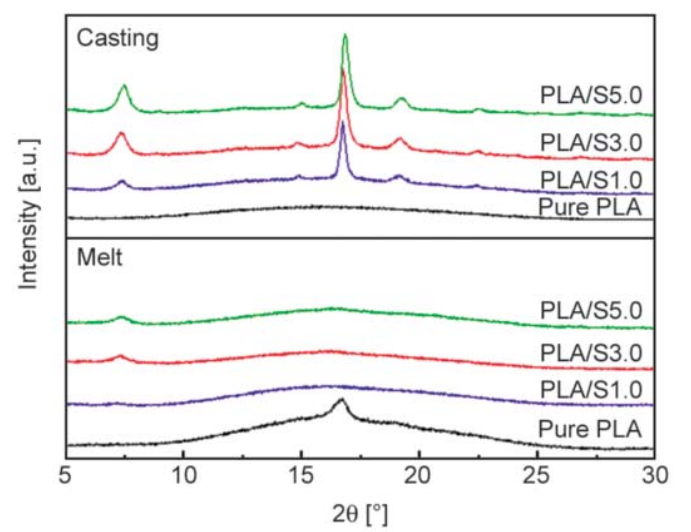

Figure 10. WAXS patterns of PLA nanocomposites obtained by casting and melting.

surface area and zeolitic channels, with the increase of Sep content more amounts of residual chloroform released from the channels of Sep, altering the crystallization behaviour.

Figure 10 shows the WAXS pattern of the pure PLA and its nanocomposites obtained by casting. It seems that the high molecular mobility due to residual chloroform induces the amorphization of pure PLA, since no diffraction peak appears in the $2 \theta$ range. The nucleating effect of Sep is confirmed. For all Sep contents, the main representative reflections of the orthorhombic $\alpha$-form of PLA crystal appear at $2 \theta=16.7^{\circ}(200 / 110), 19.1^{\circ}(203), 22.4^{\circ}(211)$ and $26.7^{\circ}(310)$. The evident reflection at $2 \theta=7.5^{\circ}$ is related to the Sep (110) basal plane. It can be observed that the intensity of this reflection increases with Sep content.

The melting process results in significant changes on the crystalline nature of the PLA nanocomposites, as can be seen in Figure 10. For the pure PLA the emergence of a reflection centred at $2 \theta=16.7^{\circ}$ indicates the formation of more ordered regions related to the $\alpha$-form. However, the presence of Sep does not favor the crystallization process, as seen in the casting samples. Moreover, the presence of Sep is also confirmed by the reflections centered at $2 \theta=7.5^{\circ}$. It seems that the amorphization of PLA is mainly caused by the decrease in molar mass associated to the melting process. Although the higher molecular mobility of PLA chains favours the ordering of the crystals (pure PLA), the nucleating effect of Sep is diminished. In the melting nanocomposites the chain alignments were restricted by the presence of Sep, resulting in the increase of crystallization time.

Figure 11 shows the SAXS intensity, $\left.I_{\mathrm{q}}\right)$, as a function of the scattering vector, $q$, for PLA and its 


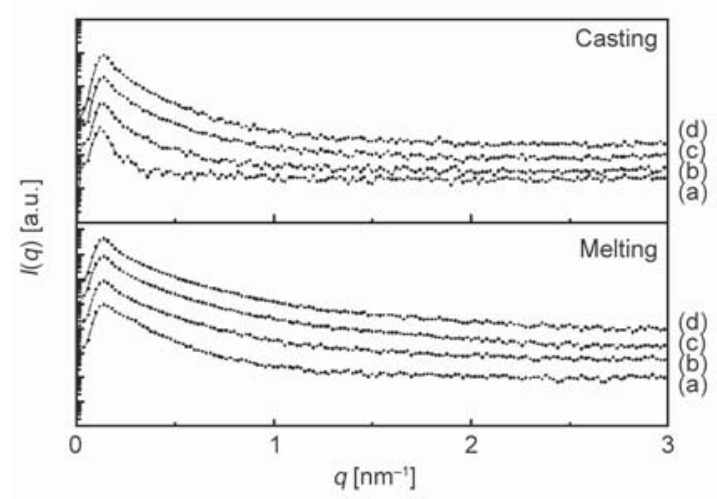

Figure 11. Logarithmic plot of SAXS intensity $\left.I_{q}\right)$ as a function of scattering vector $q$ for PLA-based nanocomposite prepared by casting and melting: (a) pure Sep, (b) PLA/S1.0, (c) PLA/S3.0 and (d) PLA/S5.0.

nanocomposites obtained by the casting and melting technique. The SAXS pattern of pure PLA obtained by casting shows an interference peak centred at $q=$ $0.12 \mathrm{~nm}^{-1}$ whereas melting PLA presents the same feature at $q=0.14 \mathrm{~nm}^{-1}$. Such feature can be explained by assuming a semi-crystalline structure of PLA, the crystalline PLA nanodomains in which the heterogeneities (dispersed in the amorphous PLA matrix) are responsible for X-ray scattering. Under this assumption, an average and most probable crystalline thickness of PLA $(d)$ can be estimated by Equation (3) [18]:

$d=\frac{2 \pi}{q_{\max }}$

A thickness of around $52 \mathrm{~nm}$ for casting and $45 \mathrm{~nm}$ for melting was found. This result is in accordance with values reported in recent papers $[19,20]$.

The $d$ values decrease when Sep is incorporated to the casting samples. However, the $d$ values do not change for the nanocomposites prepared by the melting method. Both results indicate a process of heterogeneous nucleation and growth of PLA crystallites at the surface of Sep forming crystallized nanodomains. These results are in accordance with those observed for POM. A rough estimate of the average size of the correlation volume associated to the spatial distribution of these nanodomains, $L_{\mathrm{c}}$, can be obtained by applying the Scherrer equation for SAXS, Equation (4) [18]:

$$
L_{\mathrm{c}}=\frac{4 \pi}{\Delta q}
$$

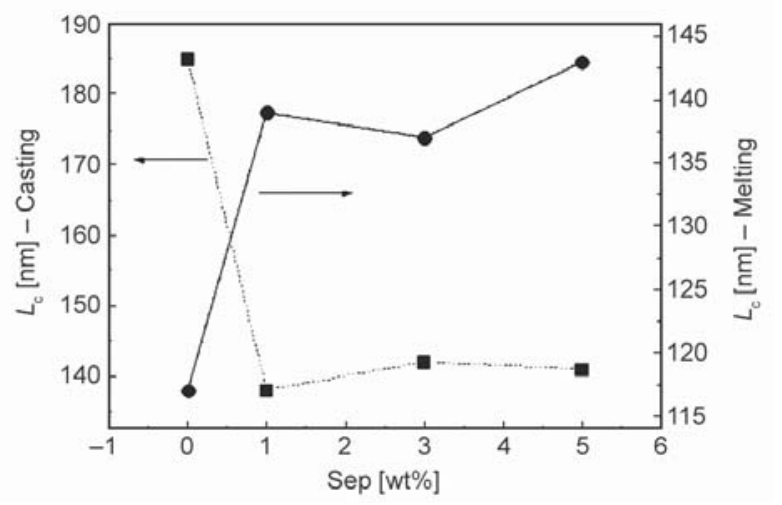

Figure 12. $L_{\mathrm{c}}$ dimensions for casting and melting samples as a function of Sep content.

where $\Delta q$ is the full-width at half-maximum (fwhm) of the correlation peak of the SAXS function. Figure 12 shows the dependence of $L_{\mathrm{c}}$ for PLA/Sep as a function of Sep content.

A decrease of $L_{\mathrm{c}}$ from $185 \AA$ (for pure PLA) to $138 \AA$ (for $1 \mathrm{wt} \% \mathrm{SEP}$ ) is observed for the casting samples. This result can be directly related to the higher dispersion of the PLA crystalline nanodomains as a consequence of nucleation effect of Sep. On the other hand, the samples obtained by the melting exhibit an increase in $L_{\mathrm{c}}$ when Sep is incorporated. This behaviour is in accordance with a decrease in the molar mass of the PLA due to the type of processing, which contributes to diminishing the average crystal size, as discussed above. Therefore, this effect leads to an increase in $L_{\mathrm{c}}$.

\section{Conclusions}

PLA nanocomposites based on sepiolite were obtained by different processing that affects the crystallization behavior. The samples produce by melting present a significant reduction on the molar mass when compared to the samples produced by casting. Additionally, residual chloroform from the casting methodology plays an important role on the crystallization process of PLA.

The spherulite size was significantly reduced for the samples prepared via melting, when compared to the casting samples. Under quiescent conditions polymers chains with lower molar mass exhibit less time for nucleus formation and subsequent growth of crystals. Additionally, an increase of nucleus density and greater amount of spherulite with reduced size may be observed when compared with pure PLA indicating that sepiolite acted as a nucleating agent. The samples obtained via melting exhibited lower 
crystallization half-time $\mathrm{t} 1 / 2$ when compared to the casting samples.

On the other hand, the presence of Sep affected the induction time in a different way. It was concluded that the chain alignments were restricted by the presence of Sep, resulting in the increase of crystallization time to the melting samples. When it comes to the nanocomposites prepared by casting, the presence of residual chloroform promoted an increase in molecular mobility altering the crystallization behaviour.

WAXS and SAXS results indicated that the sample morphology was affected by the processing. It seems that the high molecular mobility induces the amorphization of pure PLA, due to residual chloroform. For the melting pure PLA, the formation of more ordered regions related to $\alpha$-form was observed. The addition of sepiolite induced the nucleation in PLA casting. The results indicated a process of heterogeneous nucleation and PLA crystallites growth at the surface of Sep forming crystallized nanodomains.

Finally, the sepiolite caused changes in PLA structure and morphology, as well as the crystallization behavior. Furthermore, the processing type (casting or melting) strongly affect PLA characteristics and the way sepiolite affected this polymer crystallization behavior. It is clear that molar mass is one of the predominant factors in this process. Altogether, the relevance of the present study lies on the fact that it sheds some light on how the Sep content, processing and molar mass of the initial precursor can affect the crystallization of PLA.

\section{Acknowledgements}

The authors are grateful to Fundação de Amparo à Pesquisa do Estado de São Paulo (FAPESP 2017/21612-5) for financial support.

\section{References}

[1] Rasal R. M., Janorkar A. V., Hirt D. E.: Poly(lactic acid) modifications. Progress in Polymer Science, 35, 338356 (2010). https://doi.org/10.1016/j.progpolymsci.2009.12.003

[2] Wu J., Zou X., Jing B., Dai W.: Effect of sepiolite on the crystallization behavior of biodegradable poly(lactic acid) as an efficient nucleating agent. Polymer Engineering and Science, 55, 1104-1112 (2015).

https://doi.org/10.1002/pen.23981
[3] Fukushima K., Fina A., Geobaldo F., Venturello A., Camino G.: Properties of poly(lactic acid) nanocomposites based on montmorillonite, sepiolite and zirconium phosphonate. Express Polymer Letters, 6, 914-926 (2012).

https://doi.org/10.3144/expresspolymlett.2012.97

[4] Hamad K., Kaseem M., Yang H. M., Deri F., Ko Y. G.: Properties and medical applications of polylactic acid: A review. Express Polymer Letters, 9, 435-455 (2015). https://doi.org/10.3144/expresspolymlett.2015.42

[5] De Santis F., Pantani R., Titomanlio G.: Nucleation and crystallization kinetics of poly(lactic acid). Thermochimica Acta, 522, 128-134 (2011).

https://doi.org/10.1016/j.tca.2011.05.034

[6] Aliotta L., Cinelli P., Coltelli M. B., Righetti M. C., Gazzano M., Lazzeri A.: Effect of nucleating agents on crystallinity and properties of poly (lactic acid) (PLA). European Polymer Journal, 93, 822-832 (2017). https://doi.org/10.1016/j.eurpolymj.2017.04.041

[7] Feng Y., Ma P., Xu P., Wang R., Dong W., Chen M., Joziasse C.: The crystallization behavior of poly(lactic acid) with different types of nucleating agents. International Journal of Biological Macromolecules, 106, 955962 (2018).

https://doi.org/10.1016/j.ijbiomac.2017.08.095

[8] Tang H., Chen J-B., Wang Y., Xu J-Z., Hsiao B. S., Zhong G-J., Li Z-M.: Shear flow and carbon nanotubes synergistically induced nonisothermal crystallization of poly(lactic acid) and its application in injection molding. Biomacromolecules, 13, 3858-3867 (2012). https://doi.org/10.1021/bm3013617

[9] Li H., Huneault M. A.: Effect of nucleation and plasticization on the crystallization of poly(lactic acid). Polymer, 48, 6855-6866 (2007).

https://doi.org/10.1016/j.polymer.2007.09.020

[10] de Lima J. A., Camilo F. F., Faez R., Cruz S. A.: A new approch to sepiolite dispersion by treatment with ionic liquids. Applied Clay Science, 143, 234-240 (2017). https://doi.org/10.1016/j.clay.2017.03.032

[11] Fukushima K., Tabuani D., Camino G.: Nanocomposites of PLA and PCL based on montmorillonite and sepiolite. Materials Science and Engineering: C, 29, 14331441 (2009). https://doi.org/10.1016/j.msec.2008.11.005

[12] González A., Dasari A., Herrero B., Plancher E., Santarén J., Esteban A., Lim S-H.: Fire retardancy behavior of PLA based nanocomposites. Polymer Degradation and Stability, 97, 248-256 (2012).

https://doi.org/10.1016/j.polymdegradstab.2011.12.021

[13] Favaro M. M., Rego B. T., Branciforti M. C., Bretas R. E. S.: Study of the quiescent and shear-induced crystallization kinetics of intercalated PTT/MMT nanocomposites. Journal of Polymer Science Part B: Polymer Physics, 48, 113-127 (2010). https://doi.org/10.1002/polb.21852 
[14] Jalali A., Shahbikian S., Huneault M. A., Elkoun S.: Effect of molecular weight on the shear-induced crystallization of poly(lactic acid). Polymer, 112, 393-401 (2017).

https://doi.org/10.1016/j.polymer.2017.02.017

[15] Doi M.: Explanation for the 3.4 power law of viscosity of polymeric liquids on the basis of the tube model. Journal of Polymer Science: Polymer Letters Edition, 19, 265-273 (1981).

https://doi.org/10.1002/pol.1981.130190507

[16] Zang Y. H., Muller R., Froelich D.: Influence of molecular weight distribution on viscoelastic constants of polymer melts in the terminal zone. New blending law and comparison with experimental data. Polymer, 28, 1577-1582 (1987).

https://doi.org/10.1016/0032-3861(87)90362-4
[17] Coppola S., Grizzuti N., Maffettone P. L.: Microrheological modeling of flow-induced crystallization. Macromolecules, 34, 5030-5036 (2001).

https://doi.org/10.1021/ma010275e

[18] Guinier A., Fournet G.: Small-angle scattering of Xrays. Wiley, New York (1955).

[19] Yang J., Pan H., Li X., Sun S., Zhang H., Dong L.: A study on the mechanical, thermal properties and crystallization behavior of poly(lactic acid)/thermoplastic poly(propylene carbonate) polyurethane blends. RSC Advances, 7, 46183-46194 (2017). https://doi.org/10.1039/C7RA07424G

[20] Radjabian M., Kish M. H., Mohammadi N.: Structureproperty relationship for poly(lactic acid) (PLA) filaments: physical, thermomechanical and shape memory characterization. Journal of Polymer Research, 19, 9870/1-9870/10 (2012).

https://doi.org/10.1007/s10965-012-9870-0 